\title{
Oestrogenic activity of mimosine on MCF-7 breast cancer cell line through the ERa- mediated pathway
}

\begin{abstract}
Hormone replacement therapy has been a conventional treatment for postmenopausal symptoms in women. However, it has potential risks of breast and endometrial cancers. The aim of this study was to evaluate the oestrogenicity of a plant-based compound, mimosine, in MCF-7 cells by in silico model. Cell viability and proliferation, ER $\alpha$-SRC1 coactivator activity and expression of specific ER $\alpha$-dependent marker TFF1 and PGR genes were evaluated. Binding modes of 17 $\beta$-oestradiol and mimosine at the ER $\alpha$ ligand binding domain were compared using docking and molecular dynamics simulation experiments followed by binding interaction free energy calculation with molecular mechanics/Poisson-Boltzmann surface area. Mimosine showed increased cellular viability $(64,450$ cells $/ \mathrm{ml})$ at $0.1 \mu \mathrm{M}$ with significant cell proliferation (120.5\%) compared to 17 $\beta$-oestradiol (135.2\%). ER antagonist tamoxifen significantly reduced proliferative activity mediated by mimosine (49.9\%). Mimosine at $1 \mu \mathrm{M}$ showed the highest ER $\alpha$ binding activity through increased SRC1 recruitment at $186.9 \%$. It expressed TFF1 (11.1-fold at $0.1 \mu \mathrm{M})$ and PGR (13.9-fold at $0.01 \mu \mathrm{M})$ genes. ER $\alpha$-mimosine binding energy was $-49.9 \mathrm{~kJ} / \mathrm{mol}$, and it interacted with Thr347, Gly521 and His524 of ER $\alpha$ LBD. The results suggested that mimosine has oestrogenic activity.
\end{abstract}

Keyword: MCF-7 cell line; TFF1 and PGR genes; Mimosine; Oestrogenic activity 